\title{
ASPHER's Values, Vision, Mission and Aims: A Working Paper
}

\author{
Theodore H. Tulchinsky, MD, MPH, ${ }^{1}$ \\ Christopher A. Birt, MA, MSc, MB, Bchir, FREP, FFPH, DRCOG, ${ }^{2}$ \\ Ramune Kalediene, MD, MPH, $\mathrm{PhD},{ }^{3}$ \\ André Meijer, $\mathrm{MSc}^{4}$
}

Citation: Tulchinsky TH, Birt CA, Kalediene R, Meijer A. ASPHER's values, vision, mission and aims: a working paper. ASPHER: December 2007. Available from URL: http://2011.aspher.org/pg/file/read/523/asphers-values-vision-missionand-aims-a-working-paper-dec-2007 (Accessed 9 July 2012).

\section{PREFACE}

Public health challenges develop over time and vary across countries. Society changes as do population health threats, and public health systems accordingly attempt to adapt to change. As reflected in ASPHER's activities, public health training programmes must reflect these continuously developing changes in a dynamic way. From time to time all organisations need to revise their mission statements and the ethical context for their activities as part of the process of adaptation to change.

Theodore Tulchinsky, together with Christopher Birt, Ramune Kalediene and André Meijer, members of the ASPHER Executive Board, prepared this Working Paper. They take a wide perspective and context for ASPHER's mission, addressing the ethics, values, vision and aims of the organisation, including some early targets for its activities.

\footnotetext{
${ }^{1}$ Braun School of Public Health and Community Medicine, Hebrew Universtiy-Hadassah, Ein Karem, Jerusalem, Israel.

${ }^{2}$ Department of Public Health, University of Liverpool. Liverpool, UK.

${ }^{3}$ Faculty of Public Health, Medical Academy, Lithuanian University of Health Sciences Kaunas, Lithuania.

${ }^{4}$ Faculty of Health, Medicine and Life Sciences, Maastricht University, The Netherlands.
}

Corresponding Author Contact Information: Theodore H. Tulchinsky at tedt@hadassah. org.il; Braun School of Public Health and Community Medicine, Hebrew UniverstiyHadassah, Ein Karem, Jerusalem, Israel. 
The Executive Board approved this Working Paper, under development for more than a year, as a basis for continuing discussion, so enabling the possibility for members to agree formally upon ASPHER's values, vision, mission and aims. The first opportunity for such discussion will offer itself at the Annual Conference in Valencia at the end of October this year.

Suresnes, 2 October 2007

Anders Foldspang

President - ASPHER

\section{PREAMBLE}

The peoples of Europe have benefited greatly from the startling successes of modern public health of the 19th and 20th centuries, which has brought sanitation, environmental and occupational health, vaccination, control of infectious diseases, safer and healthier foods, healthier mothers and babies, family planning, declining mortality from coronary heart disease and stroke, as well as from motor-vehicle crashes, and recognition of tobacco use as a major health hazard. The result is increased longevity, with improved health standards and quality of life for the peoples of the industrialized countries. But this improvement is far from uniform for all population groups and countries across Europe, with many countries in post-Soviet transition and other poor and developing countries still suffering from low health standards; in many such countries the New Public Health remains a novel and challenging concept.

Public health developed on the basis of, and continues to rely upon, a wide spectrum of available social, legislative as well as biomedical and environmental interventions. Health promotion is incorporated within this increasing scope of public health, and it addresses complex public health problems that are largely influenced by social conditions as well as by individual and group knowledge, attitudes, practices, and behaviours. This complex of causation and of intervention approaches applies in prevention and control of HIV, cardiovascular diseases, motor vehicle injury, mental health, threatened pandemics, and terrorism, as well as in communicable diseases and in many other health problems facing individuals, groups and communities. European schools of Public Health, and ASPHER as their association, have a continuing role in promoting new public health policies as dictated by changing epidemiology and as enabled by new technologies.

The ethical base of public health in Europe developed in the context of the 19th and early 20th century successes, and was codified following 
lessons learned from the corruption by dark forces, using eugenics theories to justify the killing hundreds of thousands of helpless individuals, genocide and the Holocaust, with the killing of millions in efficient systems of mass murder. The threats of genocide, ethnic cleansing and terrorism have departed from neither the European nor the world stages, and the utmost degree of vigilance is required to prevent their recurrence. As in the case of war, these constitute grave threats to public health and international human rights. The lessons learned from the 20th century tragedies help us today to address increasingly complex ethical issues in public health, by balancing the rights of the individual with those of the community.

The European Region is widely diverse in many characteristics, including those relating to socio-economic and health status. The inequities between and within countries are challenges to the basic European consensus of social solidarity. European Schools of Public Health, and ASPHER as their association, have a key role to play in promoting high quality professional education for public health, including professional, technical and ethical aspects of public health practice, in order to achieve the goals of high levels of health for all in a new Europe.

\section{ASPHER}

ASPHER is an independent non-for-profit agency established in 1966, representing schools of public health and other public health post graduate education and programmes. These schools and other programmes prepare students for careers in service or academic public health, including through acquisition of academic degrees in public health at all levels (Bachelors, Masters and Doctorate levels).

ASPHER as an organization represents the academic component of development of the education and training of the public health workforce of Europe for the future.

ASPHER has direct roles, not only in promoting the interests of its members, but also in the widest possible implementation of the Bologna Declaration as it applies to academic education and research in the European Region, promoting equity, not only in the context of health standards, but also in that of education and recognition of qualifications and accreditation.

In this context, therefore, ASPHER here reflects full and active participation in improving the health of the peoples of Europe. This is of key significance, not only for the many countries still in transition or development with currently poor standards of public health, but throughout the whole European Region. The professional and ethical aspects of public 
health are vital not only to the educational goals of participating members, but also to the public health movement as a whole.

All of this should be seen in the context both of a reaffirmation of basic principles of ethics and values for the modern public health movement, and also within that of collaboration both with governmental and other nongovernmental organisations, and also with academic bodies.

ASPHER's role therefore includes the promotion of high quality educational environments and of the highest standards of public health practice; however, ASPHER also has a further role which includes full participation in the wider public health movement, with direct concern for both quality of health and equity in health, in each country, across Europe and globally.

\section{ASPHER'S VISION FOR HEALTHY COMMUNITIES}

This envisages healthy people and communities living in peace, social solidarity, equity, with protection of guaranteed human rights, in a healthier, safer and more equitable world.

\section{Mission}

The mission of ASPHER is to promote education, research and service in public health, in order to foster a creative and dynamic academic and practical educational infrastructure for public health workforce development.

\section{Objectives}

1. To promote national, European, and international efforts to improve the organization and standards for public health education and training so as to assure and support a competent public health and personal health care workforce operating within the context both of adequate professional support and working conditions, and of an appropriate standard of living.

2. To promote public awareness, policy, and support for mentoring academic environments conducive to the enabling and promotion of high quality research, education, training and service in the New Public Health, in keeping with the Bologna Agreement and other international agreements and collaboration to achieve these ends.

3. To promote both epidemiological and health services, including encouragement for the evaluation of effectiveness, accessibility, quality and equity of personal and population-based health services. 
4. To promote peer review in research and educational contexts including national and international accreditation systems so as to raise standards and ensure equitability in professionalism in public health across the European Region.

\section{ASPHER'S ROLE IN THE PUBLIC HEALTH CONTEXT IN EUROPE AND GLOBALLY}

1. To participate in collaborative efforts involving international, European regional, national and community partnerships to identify, diagnose, investigate and solve individual and community health threats.

2. To promote universal assurance of equity in health, with provision to meet the needs of groups at special disadvantage or health risk.

3. To promote national, European and international efforts in systematic monitoring of the health status of nations and communities, through improved population-based health information systems, including inter-linkage between multiple datasets to identify health problems at the international, European, regional, national and local community levels.

4. To promote and advocate policies, plans and funding systems for adequate financial and political support needed for improvement and equity in individual, community, national, European and international health, through collaboration to inform, educate, and assist policy makers, health providers, and populations about health issues related to both individual and community health risks and to potential solutions.

5. To promote policies and management of health resources so as to provide efficient, effective and equitable care needed for personal and community health services, and to assure the provision of health care to groups at special disadvantage or health risk.

6. To promote legislation, regulation and enforcement of these, so as to promote and to protect health and to ensure safety.

7. To promote development and reform of policies and of systems for economic analysis and management of health resources, so as to provide efficient, effective and equitable care needed for personal and community health services within national health and public health systems.

8. To promote high professional and ethical standards for evidence-based public health services at international standards. 


\section{ASPHER'S CURRENT (2007) TARGETS FOR PUBLIC HEALTH EDUCATION, TRAINING AND RESEARCH}

1 To support existing programmes, and to promote and to mentor development of new academic centres in public health with high standards of excellence in teaching, research and service delivery, in all European countries engaged in education of health personnel.

2. To promote provision of high quality of educational environments for multidisciplinary education at technical, undergraduate and postgraduate university levels throughout the European Region.

3. To promote maximum involvement of schools of public health in the higher specialist education of future senior public health professionals, and in the continuing education and professional development of those already in senior positions in public health services.

4. To develop and to promote awareness and acceptance of high standards of professional and ethical guidelines for public health education and practice throughout the European Region.

5. To promote requirements for academic education to MPH degree level for those likely to be appointed to leadership positions in the health sector in countries throughout European Region.

6. To promote national and European accreditation systems so as to assure quality of education in the New Public Health.

7. To develop the European credit system for Bachelors, Masters and Doctoral education and training in the New Public Health.

8. To promote implementation of the Bologna Agreement for a new approach to public health education at appropriate technical, undergraduate, masters and $\mathrm{PhD}$ levels, and to encourage acceptance of this by national ministries of health and of education in all countries across the European Region.

9. To promote adequate financial support and standards for research, so as to reach new insights and to promote innovative solutions to individual, risk group, national and international health problems.

10. To promote research into social, epidemiological and biological aspects of the New Public Health, and its best practices, with a view to ensuring the adoption of the highest standards of good practice, both across the European Region and internationally. 


\section{JUSTIFICATION}

ASPHER as an organization represents the academic component of development of education and training of the public health workforce of the Europe for the future, in keeping with the Bologna Agreement of 1999, now in the process of being implemented in most of the countries of the European Region.

ASPHER's Guiding Principles therefore include the following:

1. To promote high standards of public health workforce education and training, including technical, academic and professional preparation and education, in keeping with the spirit and intent of the Bologna Agreement,

2. To ensure protection of human rights in health, in keeping with the historic ethical principles as based on the Sanctity of Human Life, the Nuremberg Trials, the Universal Declaration of Human Rights, and the Helsinki Accords,

3. To promote respect for international, national and community rights and responsibilities in the context of public health practice of the highest standards.

4. To advocate and promote the highest standards of public health practice, based on the cumulative evidence of good science and of good public health practices, as developed and experienced in leading countries, and as promoted by recognised international and national professional bodies.

This paper presents the values, mission, and current aims of the organization such that they reflect full and active participation in improving the health of the peoples of Europe. This is of key significance, not only for the many countries still in transition or development with currently poor standards of public health, but throughout the whole European Region. This Working Paper outlines professional and ethical aspects of public health which are vital, not only to the educational goals of participating members, but also to the public health movement as a whole. 